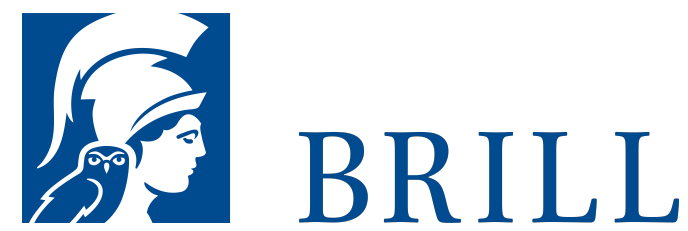

\title{
Das Buch des Wissens
}

Gespräche mit den großen Geistern unserer Zeit

Authors: Constantin von Barloewen, Gala Naoumova, and Constantin von Barloewen

Wie schön wäre es, grundsätzliche Gespräche heute noch aufgezeichnet zu haben von André Gide, Henry James, Marcel Proust, Walt Whitman ... So entstand die Vision einer interkulturellen Bibliothek, welche die großen Geister unserer Zeit für die Nachwelt speichern würde. Es wurden Protagonisten gewählt, die - jeder auf seinem Gebiet - das vergangene Jahrhundert wesentlich geprägt hatten, stets mit dem Blick auf das 21. Jahrhundert, in dem wir uns jetzt befinden. Sie sollten fachübergreifend denken, in der Kunst, der Literatur, der Musik, der Philosophie, den Religions- und Kulturwissenschaften, der Anthropologie, den Naturwissenschaften; sie sollten an die Ränder des Wissens vordringen und markante, prägende Gestalten der geistigen Welt sein, die großen Einfluss über Jahrzehnte ausübten und weiter ausüben. Sie sollten weiter aufgeschlossen sein für die Kernfragen der Weltzivilisation, die grundsätzlichen offenen Fragen der "geistigen Situation“ ihrer Zeit. Die verschiedenen Weltkulturen sollten repräsentiert sein. Gespräche mit Adonis, Boutros Boutros-Ghali, Erwin Chargaff, Régis Debray, Carlos Fuentes, Nadine Gordimer, Stephen Jay Gould, Samuel Huntington, Philip Johnson, Leszek Kolakowski, Julia Kristeva, Claude Lévi-Strauss, Federico Mayor, Yehudi Menuhin, Czeslaw Milosz, Oscar Niemeyer, Amos Oz, Raimon Panikkar, Paul Kardinal Poupard, Ilya Prigogine, Arthur... 
For more information see brill.com

Order information: Order online at brill.com +44330 333 0049 | customerservices@brill.com Submission information: brill.com/authors

Titles published by Brill | Fink, Brill | mentis or Brill | Schöningh: +49(o)715413279216| brill@brocom.de 